\title{
The effect of nutritional stress on sperm motion characteristics and sexual behaviour of rams in a semi-arid tropical environment
}

\author{
D. Kumar, K. De' ${ }^{1}$ V.K. Saxena and S.M.K. Naqvi \\ Central Sheep and Wool Research Institute (CSWRI), Division of Animal Physiology and Biochemistry \\ Avikanagar-304501, Rajasthan, India
}

KEY WORDS: ram, $F e c B$, nutritional stress, semen features, sexual behaviour, testosterone

\begin{abstract}
A major problem in sheep rearing is scarcity of feed during the summer and winter in semi-arid tropics. A study was conducted to assess the sperm motion characteristics and sexual behaviour of Garole x Malpura $\mathrm{x}$ Malpura (GMM) rams subjected to nutritional stress. Eighteen adult GMM rams were randomly allocated into three groups of six animals each: $\mathrm{G} 1$ (control; fed maintenance requirement), G2 (fed $20 \%$ less than maintenance) and G3 (fed 30\% less than maintenance). The animals were stall-fed with a diet consisting of $70 \%$ roughage and $30 \%$ concentrate. The study was conducted for eight weeks during the spring. Semen collection was done weekly at 08:00. Semen was evaluated by a computer-assisted sperm analysis technique. Sexual behaviours were also recorded at the time of semen collections. The proportion of rapid, medium and slow motile sperm, and average path velocity varied significantly $(P<0.05)$ among the groups. The time for seeking females significantly $(P<0.05)$ decreased in $\mathrm{G} 3$, while the refractory period significantly $(P<0.05)$ increased in $\mathrm{G} 2$. The testosterone concentration was significantly $(P<0.05)$ lower in $\mathrm{G} 2$ and $\mathrm{G} 3$ as compared with $\mathrm{G} 1$. The results indicate that GMM rams compromised their reproductive performance under nutritional stress imposed by $30 \%$ feed restriction of their maintenance diet during a feed scarcity period.
\end{abstract}

${ }^{1}$ Corresponding author: e-mail: kalyande2007@gmail.com
(Oldham et al., 1978). Under an extensive system of management, the level of nutrition has a more severe impact on ram reproduction than the photoperiod (Mukasa-Mugerva and Ezaz, 1992; Perez et al., 1997). In this management system, lack of adequate year-round feed resources is probably major factor in low animal production in arid and semi-arid regions in the world (Ben Salem and Smith, 2008; Kawas et al., 2010).

Undernutrition has an adverse effect on male reproduction (Cheah and Yang, 2011). Malpura is a breed well adapted to semi-arid tropical regions. Nevertheless, nutritionally induced higher and lower body conditioned Malpura rams perform inferiorly 
to moderate body conditioned Malpura rams in terms of most reproductive parameters (Maurya et al., 2010). The Booroola Fecundity gene $(F e c B)$ belongs to transforming growth factor $\beta$ (TGF- $\beta$ ) superfamily (Fabre et al., 2006). The $F e c B$ locus is situated in the region of ovine chromosome 6 and contains the bone morphogenetic protein receptor 1B (BMPR1B) gene. The mutation corresponds to A to $G$ transition at nucleotide position 746 of the cDNA resulting in non-synonymous substitution of glutamine with an arginine corresponding to position 249 of the mature protein (Mulsant et al., 2001; Wilson et al., 2001). In India, at our institute the $F e c B$ mutation from Garole sheep (a breed for a hot and humid environment) was introduced into the Malpura breed to produce Garole $\times$ Malpura $\times$ Malpura (GMM) cross-bred sheep. It is a wellestablished fact that male animals have significant contribution to the genetic and reproductive improvement of a flock. There is, however, a paucity of information on the reproductive performance of rams under nutritional stress as compared with female animals. Moreover, it is necessary to know the nutritional adaptability of GMM rams in terms of reproductive performance under a scarcity period to propagate this breed in semi-arid regions. Therefore, the present study was conducted to assess the effect of nutritional stress on sperm motion characteristics and sexual behaviour of GMM rams.

\section{Material and methods}

\section{Experimental location}

The experiment was conducted at the ICARCentral Sheep and Wool Research Institute (ICARCSWRI) farm, which is located at $75^{\circ} 28^{\prime} \mathrm{E}$ longitude and $26^{\circ} 26^{\prime} \mathrm{N}$ latitude and at an altitude of $320 \mathrm{~m}$ above mean sea level. This location has the semiarid environment occurring in India. The climate of this region is tropical. The average annual minimum and maximum ambient temperature ranges from $4^{\circ} \mathrm{C}$ to $46^{\circ} \mathrm{C}$. The mean annual relative humidity ranges from $20 \%$ to $85 \%$. The annual rainfall in this area ranges from 200 to $500 \mathrm{~mm}$ with an erratic distribution throughout the year. The experiment was carried out during February and March, which is a pleasant, stress-free season for sheep. The mean environmental temperatures, relative humidity, wind velocity and temperature-humidity index (THI) during the study period ( 8 weeks) are listed in Table 1. THI was calculated by the formula described by Marai et al. (2007).

\section{Animals}

The GMM is a prolific crossbred sheep evolved at ICAR-CSWRI (Avikanagar, India) by introgression of the $F e c B$ gene from Garole to the Malpura breed. Eighteen adult GMM rams (2-4 years old) with a mean body weight of $41.75 \pm 1.80 \mathrm{~kg}$ were used in this study. All of the rams were descendants of the same founder populations and were carriers of the $F e c B$ gene, which shows the genetic homogeneity of the rams of each group. The $F e c B$ genotyping of rams was done by forced restriction fragment lenght polymorphism-PCR (RFLP-PCR) technique using the protocol of Wilson et al. (2001) as described by Kumar et al. (2006). The animals were housed in well-ventilated sheds made of asbestos roofing and open from the side, and were maintained under proper hygienic conditions. The animals had ad libitum access to good quality drinking water. Prophylactic measures against sheep diseases like sheep pox, peste des petits ruminants, enterotoxaemia, endoand ectoparasitic infestations were carried out as prescribed by the Animal Health Division of the Institute to ensure that the animals were in a healthy condition throughout the study.

\section{Experimental procedure}

The present study was conducted for 8 weeks. The first week was the adaptation period and was used to estimate the maintenance requirement for feed. Recording and sample collection started from the $2^{\text {nd }}$ week. The 18 rams were allocated randomly into three groups of six animals each: $\mathrm{G} 1 \mathrm{n}=6$; control), G2 ( $n=6 ; 20 \%$ less feed) and G3 $(n=6$; $30 \%$ less feed). The animals were stall fed with a diet consisting of $70 \%$ roughage and $30 \%$ concentrate, $\left(\mathrm{g} \cdot \mathrm{kg}^{-1}\right.$ : barley 650 , ground nut cake 320 , minerals 30 including $\mathrm{NaCl} 10$, with crude protein 180 and total digestible nutrients 650). The G1 rams were provided with feed equivalent to their maintenance requirement, while $\mathrm{G} 2$ received $20 \%$ less feed than their maintenance requirement, and G3 rams with $30 \%$ less than maintenance. This feeding schedule began from the $2^{\text {nd }}$ week of the experiment. In the $1^{\text {st }}$ week the individual animals' maintenance requirements were determined. On the basis of this result, the feed of individual animals was restricted to induce nutritional stress. Permission for subjecting the animals to nutritional stress was obtained from the Institute's Ethics Committee before conducting the experiment.

\section{Sexual behaviour and semen evaluation}

The different types of sexual behaviour of rams, i.e. searching for females, number of mounts for first 
Table 1. Mean and SEM of climatological data during the experimental period

\begin{tabular}{|c|c|c|c|c|c|c|c|c|}
\hline \multirow{2}{*}{ Day time } & \multicolumn{4}{|c|}{ Temperature, ${ }^{\circ} \mathrm{C}$} & \multirow{2}{*}{$\mathrm{RH}, \%$} & \multirow{2}{*}{ THI } & \multirow{2}{*}{$\begin{array}{l}\text { Wind velocity, } \\
\mathrm{m} \cdot \mathrm{s}^{-1}\end{array}$} & \multirow{2}{*}{$\begin{array}{l}\text { Day length, } \\
\mathrm{h}\end{array}$} \\
\hline & maximum & minimum & dry bulb (db) & wet bulb (wb) & & & & \\
\hline \multirow[t]{2}{*}{ Morning } & $29.28 \pm 0.83$ & $13.97 \pm 0.41$ & $17.83 \pm 0.54$ & $16.11 \pm 1.19$ & $52.60 \pm 2.68$ & $16.02 \pm 0.67$ & & \\
\hline & & & & & & & 0.17 & $8.83 \pm 0.22$ \\
\hline Evening & $31.14 \pm 0.63$ & $17.18 \pm 0.68$ & $27.59 \pm 0.90$ & $18.88 \pm 0.52$ & $46.80 \pm 1.98$ & $22.66 \pm 1.04$ & & \\
\hline
\end{tabular}

$\mathrm{RH}$ - relative humidity, THI - temperature-humidity index; the meteorological data were recorded at morning 07:00 and afternoon 14:00; temperature-humidity index was calculated with the formula of: $\mathrm{THI}=\mathrm{db}{ }^{\circ} \mathrm{C}-\left\{(0.31-0.31 \mathrm{RH})\left(\mathrm{db}{ }^{\circ} \mathrm{C}-14.4\right)\right\}$ given by Marai et al. (2007)

ejaculation, time taken for first ejaculation, latency period, number of mounts for second ejaculation and time taken for second ejaculation were evaluated at the time of semen collection. Semen samples were collected from the rams using an artificial vagina at weekly intervals. The rams were exposed one by one and allowed to mount an oestrus ewe in the semen collection shed. The oestrus ewes were restrained in a service crate. Each ram was scheduled in a random order for two consecutive ejaculations. After ejaculation, the semen samples were immediately taken to the laboratory and evaluated for: 1. volume: measured directly in millilitres to the nearest $0.1 \mathrm{ml}$ using a graduated glass collection cup, 2. concentration: determined using a spectrophotometer, previously calibrated with a haemocytometer, and expressed as $10^{6} \cdot \mathrm{ml}^{-1}$, and 3. sperm motion characteristics: objectively evaluated by a computer-assisted sperm analysis (CASA) technique using a motility analyzer Hamilton-Thorn Biosciences HTM-IVOS version 12.1 M (Beverly, MA, USA; Maurya et al., 2010).

Just prior to CASA analysis, each sample was diluted to approximately $25 \times 10^{6}$ sperms per $\mathrm{ml}$ with normal saline solution and kept at $37^{\circ} \mathrm{C}$ during the entire experiment so that the time elapsed between semen dilution and CASA was very small and the sperm survived until completion of analysis. The semen analyser was set-up as follows: image type: phase contrast; frames at frame rate: 30 at $60 \cdot \mathrm{s}^{-1}$; minimum contrast: 60 ; low and high static size gates: 0.8 to 6.25 ; low and high static intensity gates: 0.25 to 1.50 ; low and high static elongation gates: 20 and 70; default cell size: 5 pixels; default cell intensity: 55; magnification: 1.89 . Twenty microlitres of the diluted sample were placed in a prewarmed Makler counting chamber $(10 \mu \mathrm{m}$ deep, Sefi-Medical Instruments Ltd., Haifa, Israel) and 5 fields per chamber were examined at $37^{\circ} \mathrm{C}$ in the analyser.

The parameters measured with the analyser were: curvilinear velocity (VCL, $\mu \mathrm{m} \cdot \mathrm{s}^{-1}$ ), average path velocity (VAP, $\mu \mathrm{m} \cdot \mathrm{s}^{-1}$ ), straight line velocity (VSL, $\mu \mathrm{m} \cdot \mathrm{s}^{-1}$ ), $\%$ motility, $\%$ rapid motility $\left(\mathrm{VAP}>75 \mu \mathrm{m} \cdot \mathrm{s}^{-1}\right), \%$ medium motility $(10<\mathrm{VAP}<$ $\left.75 \mu \mathrm{m} \cdot \mathrm{s}^{-1}\right), \%$ slow motility $\left(0<\mathrm{VAP}<10 \mu \mathrm{m} \cdot \mathrm{s}^{-1}\right)$,
$\%$ linearity, \% straightness, $\%$ elongation (ratio of minor axis/major axis $\times 100$ ), area $\mu \mathrm{m}^{2}$ (major axis $\times$ minor axis), beat frequency $(\mathrm{BF}, \mathrm{Hz})$ and amplitude of lateral head displacement (ALH, $\mu \mathrm{m})$ of the spermatozoa.

\section{Testosterone estimation}

Five millilitre blood samples were collected at weekly intervals from all of the animals. A 20-gauge sterilized needle and plastic syringe was used to sample blood from the external jugular vein into tubes with heparin as the anticoagulant. Blood samples were collected at 11:00. Plasma was separated by centrifugation of blood samples at 3500 $g$ at room temperature for $20 \mathrm{~min}$ and kept frozen at $-20^{\circ} \mathrm{C}$ for testosterone estimation. Testosterone was estimated by radioimmunoassay (RIA) using a Packard Cobra II gamma counter (PC-RIA MAS, Stretec, Germany) and employing RIA kits (analytical sensitivity $0.025 \mathrm{ng} \cdot \mathrm{ml}^{-1}$; the intra-assay and inter-assay coefficient of variations were $14.8 \%$ and $15 \%$, respectively) supplied by Immunotech (France).

\section{Statistical analysis}

The data were analysed by GLM (SPSS 14.0). The linear model was used for all of the respondent variables using least squares analysis of variance. The effect of fixed factors, namely treatment (control, 20\% feed restricted, 30\% feed restricted), week (time over which experiment was carried out, 8 weeks) and also interaction of treatment and week, was analysed on the various studied parameters. Comparison of means of the different subgroups was made by Tukey's tests. The percentile data was analysed after arcsin square root transformation of the values in percentage.

\section{Results}

\section{Semen evaluation}

The effects of nutritional stress on semen parameters are described in Table 2. There was no significant effect of nutritional stress on semen volume, 
Table 2. Effect of nutritional stress on semen characteristics of GMM rams

\begin{tabular}{|c|c|c|c|c|c|}
\hline \multirow{2}{*}{ Parameters } & \multirow{2}{*}{$\mu \pm S D$} & \multicolumn{3}{|c|}{ Experimental groups } & \multirow{2}{*}{ SEM } \\
\hline & & $\overline{\mathrm{G} 1}$ & G2 & G3 & \\
\hline Volume, $\mathrm{ml}$ & $0.58 \pm 0.04$ & 0.54 & 0.64 & 0.55 & 0.06 \\
\hline Concentration, $10^{6} \cdot \mathrm{ml}$ & $3819.94 \pm 133.28$ & 4147.18 & 3588.03 & 3724.60 & 216.72 \\
\hline Motility, $\% 1$ & $67.40 \quad(84.2)$ & $68.10 \quad(85.1)$ & $64.13(80.0)$ & $67.40(84.2)$ & 1.93 \\
\hline rapid, $\%^{1}$ & $57.89 \pm 1.24(70.7)$ & $59.76^{\mathrm{a}}(73.6)$ & $61.41^{\mathrm{a}}(76.1)$ & $52.52^{b}(62.0)$ & 2.02 \\
\hline medium, $\% 1$ & $18.12 \pm 0.77(8.7)$ & $16.30^{\mathrm{a}}(6.9)$ & $16.78^{\mathrm{a}}(7.3)$ & $21.26^{b}(12.1)$ & 1.26 \\
\hline slow, $\%^{1}$ & $8.05 \pm 0.36(1.9)$ & $8.50^{\mathrm{ab}}(1.2)$ & $6.44^{\mathrm{a}}(0.9)$ & $9.24^{b}(1.6)$ & 1.45 \\
\hline$V C L, \mu \mathrm{m} \cdot \mathrm{s}^{-1}$ & $241.10 \pm 4.38$ & 238.46 & 253.18 & 231.67 & 7.125 \\
\hline VAP, $\mu \mathrm{m} \cdot \mathrm{s}^{-1}$ & $158.96 \pm 3.49$ & $164.75^{\mathrm{ab}}$ & $166.31^{a}$ & $145.81^{b}$ & 5.67 \\
\hline VSL, $\mu \mathrm{m} \cdot \mathrm{s}^{-1}$ & $131.54 \pm 3.01$ & 133.32 & 134.77 & 126.53 & 4.90 \\
\hline Linearity, $\% 1$ & $48.19 \pm 0.46(54.6)$ & $49.10 \quad(56.1)$ & 48.55 (55.2) & $46.92 \quad(52.3)$ & 0.74 \\
\hline Straightness, $\%^{1}$ & $63.27 \pm 0.40$ & $64.00 \quad(79.8)$ & $63.14(78.6)$ & 62.66 (77.9) & 0.65 \\
\hline $\mathrm{ALH}, \mu \mathrm{m}$ & $7.57 \pm 0.14$ & $6.80^{\mathrm{a}}$ & $7.84^{\mathrm{b}}$ & $8.07^{b}$ & 0.22 \\
\hline $\mathrm{BF}, \mathrm{Hz}$ & $17.67 \pm 2.67$ & 17.89 & 12.30 & 22.82 & 4.33 \\
\hline Elongation, $\%{ }^{1}$ & $46.65 \pm 0.61$ & 46.01 & 46.84 & 47.11 & 0.99 \\
\hline Area, $\mu \mathrm{m}^{2}$ & $6.67 \pm 1.01$ & 7.80 & 5.18 & 7.02 & 1.64 \\
\hline
\end{tabular}

GMM - Garole $\times$ Malpura $\times$ Malpura; G1 - control maintenance feeding, G2 - 20\% restriction of maintenance feeding, G3 - 30\% restriction of maintenance feeding; VCL - curvilinear velocity, VAP - average path velocity, VSL - straight line velocity, BF - beat frequency, ALH - amplitude of lateral head displacement; $\mu$ - indicates the general mean for the parameter; SEM - standard error of the mean; means of different groups (G1, G2 and G3) with similar superscript $(a, b)$ within a row do not differ significantly $(P>0.05)$ from each other; ${ }^{1}$ values are mean of the arcsin transformed values in percentage, whereas values in parenthesis are actual means of data

Table 3. Effect of nutritional stress on sexual behaviour of $\mathrm{GMM}^{1}$ rams

\begin{tabular}{lllllll}
\hline Indices & $\begin{array}{l}\text { Searching } \\
\text { for female, } \mathrm{s}\end{array}$ & $\begin{array}{l}\text { No. of mounting } \\
\text { for } 1^{\text {st }} \text { ejaculation }\end{array}$ & $\begin{array}{l}\text { Time taken } \\
\text { for } 1^{\text {st }} \text { ejaculation }\end{array}$ & $\begin{array}{l}\text { Latency } \\
\text { period, } \mathrm{s}\end{array}$ & $\begin{array}{l}\text { No. of mounting } \\
\text { for } 2^{\text {nd }} \text { ejaculation }\end{array}$ & $\begin{array}{l}\text { Time taken } \\
\text { for } 2^{\text {nd }} \text { ejaculation }\end{array}$ \\
\hline$\mu \pm$ SEM & $9.79 \pm 1.08$ & $2.51 \pm 0.18$ & $15.63 \pm 1.83$ & $56.46 \pm 4.64$ & $2.98 \pm 0.28$ & $31.91 \pm 3.92$ \\
Treatment $^{2}$ & & NS & NS & & NS & NS \\
G1 & $12.81^{\mathrm{a}}$ & 2.29 & 12.26 & $38.57^{\mathrm{b}}$ & 2.80 & 28.43 \\
$\mathrm{G} 2$ & $10.74^{\mathrm{ab}}$ & 2.71 & 20.02 & $74.46^{\mathrm{a}}$ & 3.83 & 43.34 \\
$\mathrm{G} 3$ & $5.81^{\mathrm{b}}$ & 2.52 & 14.60 & $56.34^{\mathrm{ab}}$ & 2.31 & 23.97 \\
Pooled SEM for treatment & 1.87 & 0.32 & 3.17 & 8.04 & 0.48 & 6.80 \\
Week & $\mathrm{NS}$ & $\mathrm{NS}$ & $\mathrm{NS}$ & $\mathrm{NS}$ & $\mathrm{NS}$ & $20.13^{\mathrm{b}}$ \\
1 & 12.90 & 2.72 & 14.67 & 69.67 & 2.40 & $29.87^{\mathrm{ab}}$ \\
2 & 8.94 & 3.11 & 15.11 & 66.67 & 3.67 & $24.93^{\mathrm{ab}}$ \\
3 & 9.33 & 2.50 & 13.22 & 59.40 & 3.27 & $29.73^{\mathrm{ab}}$ \\
4 & 9.89 & 2.94 & 13.78 & 54.87 & 2.13 & $44.53^{\mathrm{ab}}$ \\
6 & 7.00 & 2.28 & 10.67 & 53.07 & 4.73 & $13.20^{\mathrm{b}}$ \\
7 & 12.11 & 2.22 & 22.28 & 50.67 & 2.47 & $61.00^{\mathrm{a}}$ \\
Pooled SEM for week & 8.28 & 1.78 & 19.67 & 40.87 & 2.20 & 10.38 \\
\hline
\end{tabular}

1,2 see Table 2; $\mu$ - indicates the general mean for the parameter; SEM - standard error of the mean; means of different groups (G1, G2 and G3) with similar superscript $(a, b$ and $a b)$ within a column do not differ significantly $(P>0.05)$ from each other; means of different experimental weeks $\left(1^{\text {st }}, 2^{\text {nd }}, 3^{\text {rd }}, 4^{\text {th }}, 5^{\text {th }}, 6^{\text {th }}\right.$ and $\left.7^{\text {th }}\right)$ with similar superscript $(a, b$ and $a b)$ within a column do not differ significantly $(P>0.05)$ from each other; searching for female is the time taken by the ram to reach or search for the female to mount for the first time; latency period is the time lapse between the $1^{\text {st }}$ ejaculation and begining of mounting for $2^{\text {nd }}$ ejaculation; NS - not significant

total progressive motility, VCL, VSL, linearity or straightness of ram spermatozoa. The sperm concentration was lower in G2 and G3 as compared with G1. Although the total motile spermatozoa percentage did not differ significantly among the groups, still the percentage of rapidly motile sperm was significantly $(P<0.05)$ lower, and the percentage of medium and slow motile sperm was significantly $(P<0.05)$ higher in group G3. The VAP was also significantly $(P<0.05)$ lower in G3 rams and ALH was significantly higher in G2 and G3 as compared with control rams.

\section{Sexual behaviour}

The effect of nutritional stress on sexual behaviour is described in Table 3. It was found that 


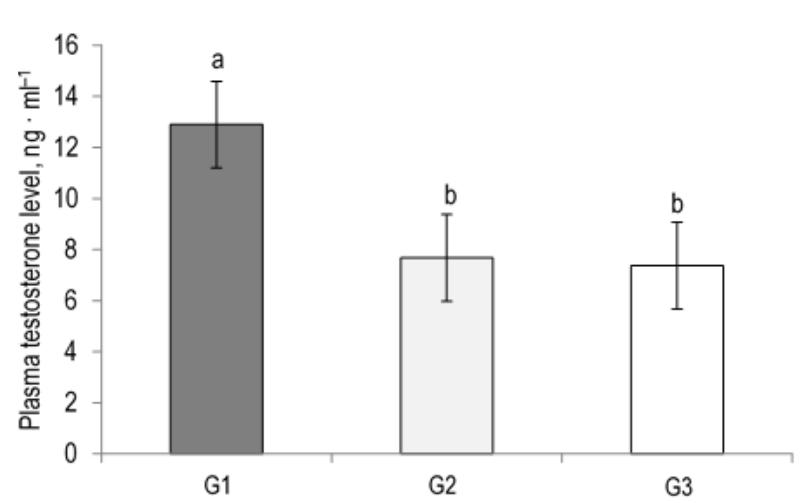

Figure 1. Effect of nutritional stress on plasma testosterone levels of Garole $\times$ Malpura $\times$ Malpura rams. G1 - control - maintenance feeding, G2 - 20\% restriction of maintenance feeding, G3 - 30\% restriction of maintenance feeding. Columns of different groups (G1, G2 and G3) with similar letter above do not differ significantly $(P>0.05)$ from each other

G3 rams spent significantly $(P<0.05)$ less time seeking a female. The number of mounts for the first ejaculation and time taken for first ejaculation were lower in G1 rams. The refractory period was significantly $(P<0.05)$ influenced by nutritional stress. It was higher in G2 rams as compared with G1 rams. However, nutritional stress had no significant effect on the number of mounts for the second ejaculation and the time taken for the second ejaculation. Furthermore, experimental week and interaction between week and treatment had no significant effect on sexual behaviour except time taken for the $2^{\text {nd }}$ ejaculation.

\section{Plasma testosterone level}

Figure 1 describes the effect of nutritional stress on the testosterone level. The mean plasma testosterone level differed significantly $(P<0.05)$ among groups. The mean plasma testosterone concentration was significantly $(P<0.05)$ lower in groups G2 and G3 as compared with G1. Further, experimental week also significantly $(P<0.01)$ influenced the plasma testosterone concentration (data not presented).

\section{Discussion}

The present experiment demonstrates the sexual adaptive capability of newly developed prolific GMM rams when they are subjected to nutritional stress. Animals need nutrients primarily for body maintenance and then for growth, production and reproduction (Martin et al., 2008).

It has already been reported that animals become gonadally regressed and sexually inactive during periods of feed scarcity and high demands of a thermoregulatory period (Schneider, 2004).
Such conditions lead to activation of neuropeptides related to the central feeding stimulatory circuit. This signal inhibits the hypothalamic-pituitarygonadal (HPG) system and gonadotropin-releasing hormone $(\mathrm{GnRH})$ secretion. Inhibition of $\mathrm{GnRH}$ secretion causes a decrease in the secretion of gonadotropin that ultimately reduces testosterone production in the gonads. In the present study, plasma testosterone was significantly $(P<0.05)$ lower in feed-restricted animals as compared with control rams and, therefore, testosterone-induced sexual behaviour was also reduced in feed-restricted animals. In a similar experiment, Maurya et al. (2010) also reported reduced testosterone levels and reproductive behaviours of Malpura rams. Malau-Aduli et al. (2003) reported that additional nutritional supplementation aids body weight gain and peaks testosterone concentration in bucks.

Scaramuzzi et al. (2006) stated that interactions between metabolites and hormones regulate the energy balance of animals. For reproduction an animal needs large amounts of energy, therefore, the energy balance of an animal is closely related to fertility (Martin et al., 2008). Changes in available energy and feed intake alter the endocrine axis and HPG axis. At the time of energy deficiency, an animal would divert the energy available for brain function and cognition that ultimately will hamper reproduction (Maurya et al., 2010). Braden et al. (1974) reported that the level of feeding influences sperm production of Merino rams. Underfed rams had lower spermatogenic activity and sperm content of the epididymis as compared with ad libitum fed rams (Hotzel et al., 1997). In present study, the sperm concentration was also lower in groups G2 and G3 as compared with G1.

A low-quality feed supply increases the number of immature spermatozoa and decreases the normal spermatozoa count in rams (Dana et al., 2000). Similarly, feed restriction reduced the total motile spermatozoa. In the present study, rapidly motile spermatozoa counts were significantly lower, whereas medium and slow spermatozoa were significantly higher in the nutritionally stressed rams. The testosterone level is a good indicator of semen quality and production. Spermiogenesis is influenced by testosterone because normal spermatozoa are dependent on Sertoli cells for their care, nourishment and division (Hafez, 1993).

The condition of the body induced by nutritional stress had a significant effect on the sexual behaviour of Malpura rams (Maurya et al., 2010). The sexual parameters recorded in the present study showed that the number of mountings for the first ejaculation, time taken for the first ejaculation, and 
latency period were smaller and shorter in group G1 as compared with G2 and G3. This shows that nutritional restriction is detrimental to sexual behaviour, while testosterone levels also decreased significantly. Kishk (2008) reported that testosterone level of Rahmani rams negatively correleated with reaction time and positively correlated with semen volume, sperm motility and sperm concentration which is in agreement with the findings of the present study in which we found decrease in testosterone level with feed restrictions.

\section{Conclusions}

The present study clearly establishes that Garole $\times$ Malpura $\times$ Malpura, a prolific crossbred of native sheep breeds of a semi-arid tropic region (Malpura) and a hot humid region breed (Garole), compromised their reproductive performance under nutritional stress imposed by $30 \%$ feed restriction of their maintenance diet. This is evident from impaired sexual behaviour, testosterone concentration and sperm motility in feed-restricted rams. The quality of semen was not affected much, however, by nutritional stress up to $20 \%$ restriction of the maintenance diet. Further detailed studies are required to determine the optimal nutritional requirement during scarcity period to maintain reproduction in rams.

\section{Acknowledgements}

The authors are very thankful to Anoop Kumar Singh, Kamal Kumar, Indu Shekawat and Saumya Bahadur for their technical help during the experiment.

\section{References}

Ben Salem H., Smith T., 2008. Feeding strategies to increase small ruminant production in dry environments. Small Rumininant Res. 77, 174-194

Braden A.W.H., Turnbull K.E., Mattner P.E., Moule G.R., 1974. Effect of protein and energy content of diet on the rate of sperm production in rams. Aust. J. Biol. Sci. 27, 67-73

Cheah Y., Yang W., 2011. Functions of essential nutrition for high quality spermatogenesis. Adv. Biosci. Biotechnol. 2, 182-197

Dana N., Tegegne A., Shenkoru T., 2000. Feed intake, sperm output and seminal characteristics of Ethiopian highland sheep supplemented with different levels of leucaena (Leucaenaleucocephala) leaf hay. Anim. Feed Sci. Tech. 86, 239-249

Fabre S., Pierre A., Mulsant P., 2006. Regulation of ovulation rate in mammals: contribution of sheep genetic models. Reprod. Biol. Endocrinol. 4 (20), 20-31

Hafez E.S.E., 1993. Reproduction in Farm Animals. $6^{\text {th }}$ Edition. Lea and Febiger, Philadelphia
Hotzel M.J., Caraty A., Martin G.B., 1997. Effect of nutrition on testicular growth in rams immunized against $\mathrm{GnRH}$. J. Reprod. Fertil. 110, 307-313

Kawas J.R., Andrade-Montemayor H., Lu C.D., 2010. Strategic nutrient supplementation of free-ranging goats. Small Ruminant Res. 89, 234--243

Kishk W.H., 2008. Interrelationship between ram plasma testosterone level and some semen characteristics. Slovak J. Anim. Sci. 41, 67-71

Kumar S., Kolte A.P., Mishra A.K., Arora A.L., Singh V.K., 2006. Identification of the FecB mutation in GarolexMalpura sheep and its effect on litter size. Small Ruminant Res. 64, 305-310

Malau-Aduli B.S., Eduvie L., Lakpini C., Malau-Aduli A.E.O., 2003. Scrotal circumference, bodyweight and serum testosterone concentration of Red Sokotoweaner bucks as influenced by dry season crop-residue supplementation. Anim. Sci. J. 74, 195-203

Marai I.F.M., El-Darawany A.A., Fadiel A., Abdel-Hafez M.A.M., 2007. Physiological traits as affected by heat stress in sheep. A review. Small Ruminant Res. 71, 1-12

Martin B., Golden E., Carlson O.D., Egan J.M., Mattson M.P., Maudsley S., 2008. Caloric restriction: impact upon pituitary function and reproduction. Ageing Res. Rev. 7, 209-224

Maurya V.P., Sejian V., Kumar D., Naqvi S.M.K., 2010. Effect of induced body condition score differences on sexual behavior, scrotal measurements, semen attributes and endocrine responses in Malpura rams under hot semi-arid environment. J. Anim. Physiol. Anim. Nutr. 94, 308-317

Mukasa-Mugerva E., Ezaz Z., 1992. Relationship of testicular growth and size to age, body weight and onset of puberty in Menz ram lambs. Theriogenology 38, 979-988

Mulsant P., Lecerf F., Fabre S., 2001. Mutation in bone morphogenetic protein receptor-IB is associated with increased ovulation rate in Booroola Merino ewes. Proc. Nat. Acad. Sci. USA 98, 5104-5109

Oldham C.M., Adams N.R., Gherardi P.B., Lindsay D.R., Mackintosh J.B., 1978. The influence of level of feed intake on sperm producing capacity of testicular tissue in the ram. Aust. J. Agr. Res. 29, 173-179

Perez C.R., Lopez A., Castrillejo A., Bielli A., Laborde D., Gastel T., Tagle R., Queirolo D., Franco J., Forsberg M., RodriguezMartinez H., 1997. Reproductive seasonality of corriedale rams under extensive rearing conditions. Acta Vet. Scand. 38, 109-117

Scaramuzzi R.J., Cambel B.K., Downing J.A., Kendall N.R., Khalid M., Gutierrez M., Somchit A., 2006. A review of the effect of supplementary nutrition in the ewe on the concentration of reproductive and metabolic hormones and the mechanism that regulate folliculogenesis and ovulation rate. Reprod. Nutr. Develop. 46, 339-354

Schneider J.E., 2004. Energy balance and reproduction. Physiol. Behav. 81, 289-317

Sejian V., Maurya V.P., Kumar K., Naqvi S.M.K., 2012. Effect of multiple stresses (thermal, nutritional, and walking stress) on the reproductive performance of malpura ewes. Vet. Med. Int. doi:10.1155/2012/471760

SPSS, 2005. SPSS for Windows, Brief Guide, Version 14.0. SPSS Inc. Chicago, IL

Wilson T., Wu X.Y., Juengel J.L. et al., 2001. Highly prolific Booroola sheep have a mutation in the intracellular kinase domain of bone morphogenetic protein IB receptor (ALK-6) that is expressed in both oocytes and granulosa cells. Biol. Reprod. $64,1225-1235$ 